\title{
Research on Class-Based Storage Strategies for Flood Control Materials Based on Grey Clustering
}

\author{
Wei Wang 1ํ, Li Huang ${ }^{2}{ }^{*}$, Weiwei Le ${ }^{3}$, Yu Zhang ${ }^{1}$, Peng Ji ${ }^{1}$ and David Proverbs ${ }^{4}$ \\ 1 College of Harbor, Coastal and Offshore Engineering, Hohai University, Nanjing 210098, China; \\ 13813826667@hhu.edu.cn (W.W.); ozzyzhang1@163.com (Y.Z.); ji_peng@163.com (P.J.) \\ 2 School of Public Administration, Hohai University, Nanjing 210098, China \\ 3 Business School, Sichuan University, Chengdu 610065, China; 2017225025125@stu.scu.edu.cn \\ 4 Computing, Engineering and Built Environment at Birmingham City University, Birmingham B4 7XG, UK; \\ david.proverbs@bcu.ac.uk \\ * Correspondence: lily8214@126.com; Tel.: +86-25-8378-7354
}

Received: 13 September 2018; Accepted: 19 October 2018; Published: 25 October 2018

check for updates

\begin{abstract}
Scientific and rational class-based storage can effectively improve the management level of flood control materials, providing assurance for the material support that is essential in flood control. Based on an analysis of the three key factors-importance, cost, and reserve-of flood control materials and combined with the correlations of different classes of materials, a comprehensive evaluation index system and a class-based model for these materials are developed using the grey clustering method. An empirical analysis is also conducted based on the realistic requirements of a warehouse of the Jiangsu provincial water conservancy and flood control materials reserve centre, which results in the proposal of a class-based materials storage strategy for this warehouse.
\end{abstract}

Keywords: flood control materials; grey clustering; class-based storage

\section{Introduction}

In the history of the development of human society, water has been regarded as an important natural resource of irreplaceable significance in the promotion of the development of social economy. However, flood hazards with frequent, multiple, and complicated occurrence have brought severe damages to the life and property of the people, especially in areas with a high flood occurrence frequency. Flood disasters are usually easily predicted and prevented compared with other natural disasters [1]. Some preparatory activities may be made in advance to prevent flooding from actually happening [2,3]. Therefore, we shall attach great importance to work related to flood control, the preparation to control and fight against great floods, and deal with emergencies.

To keep to the concept of all-time preparedness, we shall first guarantee adequate reserves and the good management of flood-prevention materials, which, as the prerequisite and safeguard of different flood-controlling measures, are of direct relation to the smooth progression of work related to flood control.

Emergency logistics are of vital significance in flood fighting, on which relevant researchers have already conducted preliminary studies. However, flood emergency preparedness lacks insight into logistical aspects [4,5]. Garrido et al. put forward a model to assist decision-makers in the logistics of a flood emergency. The model attempts to optimize inventory levels for emergency supplies as well as vehicles' availability, in order to deliver enough supplies to satisfy demands with a given probability. This methodology emerges as a valuable tool to help decision makers to allocate resources both before and after a flood occurs, with the aim of minimizing the undesirable effects of such events [6]. Leeuw et al. developed a framework of logistical aspects of emergency measures that support 
preventing the catastrophic breaching of flood defences during extreme situations. The Netherlands is taken as a reference because large parts of the country are prone to flooding. Furthermore, the Netherlands has a long-standing experience with implementing flood emergency measures. This paper is particularly focused on the role of Water Boards, the Dutch government agencies responsible for securing flood defences [7]. Alem et al. develop a new two-stage stochastic network flow model to help decide how to rapidly supply humanitarian aid to victims of a disaster within this context. The model takes into account the practical characteristics that have been neglected by the literature so far, such as budget allocation, fleet sizing of multiple types of vehicles, procurement, and varying lead times over a dynamic multiperiod horizon. By attempting to improve demand fulfilment policy, we present some extensions of the model via state-of-art risk measures, such as semi-deviation and conditional value-at-risk. A simple two-phase heuristic to solve the problem within a reasonable amount of computing time is also suggested. Numerical tests based on the floods and landslides in the Rio de Janeiro state, Brazil, show that the model can help plan and organise relief to provide good service levels in most scenarios, and how this depends on the type of disaster and resources [8]. These researches mainly focus on the macroscopical emergency logistics organization for flood control.

Flood control materials form the bedrock for flood control and provide important assurances for rescue work. As society becomes increasingly demanding of flood control, the scientific and rational storage of flood control materials has become a key condition for guaranteeing security during flood control. It has been noted that the dispatch of flood control materials from warehouses is characterised by few varieties, few batches, and large quantities. Therefore, this study analyses the warehousing and storage strategy for flood control materials, which is useful for lowering access costs, increasing warehouse space utilization, and outflow efficiency, and is, theoretically and practically, important for improving the reserve management level of flood control materials and guaranteeing supply.

A class-based storage strategy has drawn immense attention from researchers since it was proposed by Hausman [9]; moreover, this strategy has been widely applied in commercial logistics. Larson et al. conducted a study on a class-based storage strategy with the goal of increasing floor space utilisation and decreasing the material handling distance [10]. Thonemann, Byung, Ene et al. applied the turnover rate to classify items, and storage locations were assigned based on the classification results [11-13]. Brynzer, Mantel et al. proposed the concept of materials correlation using the probability of materials appearing together in the same order according to the order history as a basis for class-based storage [14,15]. Li conducted a heuristic classification of products by using an algorithm, considering the underlying factors, and grouping them to set up a highly efficient dispatch centre [16]. Using a heuristic approach, Muralidhran et al. studied a storage strategy that combined automated warehouses using both random and class-based storage [17].

Compared with the prosperity of commercial logistics, few studies exist on the class-based storage of emergency materials, and most of the existing studies are qualitative instead of quantitative. Arreola-Risa et al. hypothesised that the intervals between emergencies and the time at which emergency materials are supplied follow a certain function distribution; thereby, they studied the class-based storage of emergency materials to respond to emergencies [18]. Banomyong et al. used a Monte Carlo simulation to perform a reliable and effective validation of emergency logistics response models and recommended a framework for materials storage. In addition to the ABC classification method [19], Gajpal et al. also studied the FSN and VED classification methods and performed optimisation according to the various situations [20]. Axsater designed a heuristic algorithm for triggering emergency orders in an inventory system, maximally reducing the expected inventory cost of emergency materials in the reserve [21]. Chang addresses the analysis of the travel distance and the number of storage locations for storage location allocation methods in a warehouse system [22]. Grey clustering has been widely adopted for forecasting, estimation, and control since it was proposed by Professor Deng Julong [23,24]. Based on fuzzy clustering, Guo and Zhang classified emergency materials and explored the various emergency materials storage models [25]. However, to the best of authors' knowledge, a quantitative study on strategies for the class-based storage of emergency 
materials has been seldom reported on. Certainly, no one has investigated class-based storage strategies of flood control materials quantitatively.

Thus, the research problem addressed in this paper is how to construct class-based storage strategies for flood control materials in a quantitative manner. This study has an important practical significance and research value and can effectively fill the gap. Based on existing research results and common class-based storage strategies, this paper established an evaluation index system to classify flood control reserve materials. An evaluation model for the class-based storage of flood control materials was constructed based on grey clustering. Taking the Zhenjiang branch warehouse of the Jiangsu provincial water conservancy and flood control reserve materials centre as an example and considering the characteristics and requirements of flood control materials according to the roles and functions of different materials in flood rescue, a class-based storage management strategy was proposed to improve the warehouse outflow efficiency of flood control materials.

\section{Analysis of Storage Strategies for Flood Control Materials}

Table 1 presents the commonly used storage strategies [26] - fixed location storage, random location storage, class-based storage, class-based random storage, shared storage, and item-location coupling storage —and a comparison of their characteristics, advantages, and disadvantages.

Table 1. The comparison of the different storage strategies characteristics.

\begin{tabular}{|c|c|c|c|}
\hline Strategy & Characteristics & Advantages & Disadvantages \\
\hline $\begin{array}{l}\text { Fixed location } \\
\text { storage }\end{array}$ & $\begin{array}{l}\text { Materials are stored based on } \\
\text { the turnover rate or } \\
\text { warehouse outflow frequency } \\
\text { of materials. }\end{array}$ & $\begin{array}{l}\text { Can shorten the gap } \\
\text { between the warehouse } \\
\text { inflow and outflow } \\
\text { operations. }\end{array}$ & $\begin{array}{l}\text { Reduces the efficiency of the } \\
\text { warehouse space utilisation. }\end{array}$ \\
\hline $\begin{array}{l}\text { Random } \\
\text { location } \\
\text { storage }\end{array}$ & $\begin{array}{l}\text { Materials are stored near the } \\
\text { entrance/exit of the } \\
\text { warehouse in a sequence } \\
\text { based on the time that they } \\
\text { enter the warehouse. }\end{array}$ & Locations can be shared. & $\begin{array}{l}\text { More difficult to perform } \\
\text { inventory management; } \\
\text { reduces the warehouse } \\
\text { inflow and } \\
\text { outflow efficiency. }\end{array}$ \\
\hline $\begin{array}{l}\text { Class-based } \\
\text { storage }\end{array}$ & $\begin{array}{l}\text { Materials are stored based on } \\
\text { factors such as product } \\
\text { correlativity, fluidity, } \\
\text { dimensions and } \\
\text { characteristics. }\end{array}$ & $\begin{array}{l}\text { Good for storage of } \\
\text { hot-selling items. }\end{array}$ & $\begin{array}{l}\text { Reduces the efficiency of the } \\
\text { storage space utilisation. }\end{array}$ \\
\hline $\begin{array}{l}\text { Class-based } \\
\text { random } \\
\text { storage }\end{array}$ & $\begin{array}{l}\text { Every class of materials is } \\
\text { stored in a fixed location in a } \\
\text { warehouse zone, but the } \\
\text { location assignment } \\
\text { is random. }\end{array}$ & $\begin{array}{l}\text { Saves on the number of } \\
\text { locations; increases } \\
\text { warehouse utilisation rate. }\end{array}$ & $\begin{array}{l}\text { Makes it more difficult to } \\
\text { manage the warehouse } \\
\text { inflow and outflow of } \\
\text { materials and inventory } \\
\text { maintenance. }\end{array}$ \\
\hline $\begin{array}{l}\text { Shared } \\
\text { storage }\end{array}$ & $\begin{array}{l}\text { Different materials share the } \\
\text { same location. }\end{array}$ & $\begin{array}{l}\text { Saves storage space and } \\
\text { moving time. }\end{array}$ & $\begin{array}{l}\text { Makes management more } \\
\text { complicated. }\end{array}$ \\
\hline $\begin{array}{l}\text { Item-location } \\
\text { coupling } \\
\text { storage }\end{array}$ & $\begin{array}{l}\text { Partitioned assignment is } \\
\text { executed separately for } \\
\text { locations and materials. } \\
\text { Materials are stored in } \\
\text { fixed locations in order of } \\
\text { warehouse outflow frequency. }\end{array}$ & $\begin{array}{l}\text { Shortens the time to } \\
\text { operate the warehouse } \\
\text { inflows and outflows; } \\
\text { more suitable for } \\
\text { warehouse zone } \\
\text { management. }\end{array}$ & $\begin{array}{l}\text { High investment; operation } \\
\text { has high demands for } \\
\text { intelligence and } \\
\text { informatisation. }\end{array}$ \\
\hline
\end{tabular}

After summarising these storage strategies and principles for location assignment and considering the attributes of flood control materials, we decided to adopt the class-based fixed location storage. Given that flood control materials are characterised by few varieties, large quantities, low warehouse inflow and outflow frequencies, and strong constraints on warehouse outflow timeliness and response time, a class-based storage strategy is mostly appropriate for such materials. The strategy begins by 
sorting the materials, followed by a fixed location storage by considering attributes such as materials correlativity and utilisation frequency. The class-based storage strategy is critical for improving the warehouse outflow efficiency of the flood control materials and increasing the ability to provide support [27].

\section{Class-Based Storage Model for Flood Control Materials Based on Grey Clustering}

Grey clustering is a method for segregating observations (or subjects) based on a grey incidence matrix [28]. Based on grey clustering, the class-based storage model for flood control materials was constructed by comprehensively considering the three factors of such materials, namely, their importance, reserve, and cost, to improve the scientific basis for the class-based storage for flood control materials.

Assuming $m$ observations and every observation having $n$ attribute data, the following sequence is obtained:

$$
\mathrm{X}_{1}=\left(x_{1}(1), x_{1}(2), \ldots, x_{1}(n)\right) \mathrm{X}_{2}=\left(x_{2}(1), x_{2}(2), \ldots, x_{2}(n)\right) \mathrm{X}_{m}=\left(x_{m}(1), x_{m}(2), \ldots, x_{m}(n)\right)
$$

The observation subjects $\mathrm{X}_{1}-\mathrm{X}_{m}$ have similar lengths and are not zero. Accordingly, the following equations are obtained:

$$
\mathrm{X}_{i}^{0}=\left(x_{i}^{0}(1), x_{i}^{0}(2), \ldots, x_{i}^{0}(n)\right) \mathrm{X}_{j}^{0}=\left(x_{j}^{0}(1), x_{j}^{0}(2), \ldots, x_{j}^{0}(n)\right)
$$

$\mathrm{X}_{i}^{0}$ and $\mathrm{X}_{j}^{0}$ represent the starting-point annihilating images of $\mathrm{X}_{i}$ and $\mathrm{X}_{j}$, in which $\mathrm{X}_{i}^{0}=\mathrm{X}_{i}-$ $x_{i}(1), X_{j}^{0}=X_{j}-x_{j}(1)(i=0,1,2, \ldots, m ; j=0,1,2, \ldots, m) . X_{i}^{0}$ and $X_{j}^{0}$ are actually the sequence of $n$ -1 values. Taking $X_{i}^{0}$ as an example, we can use a broken line graph to present the $n-1$ values, as shown in Figure 1. The broken line connects points $x_{i}(2)-x_{i}(1), x_{i}(3)-x_{i}(1), \ldots, x_{i}(n)-x_{i}(1)$. It is clear that this line is made sectionally continuous.

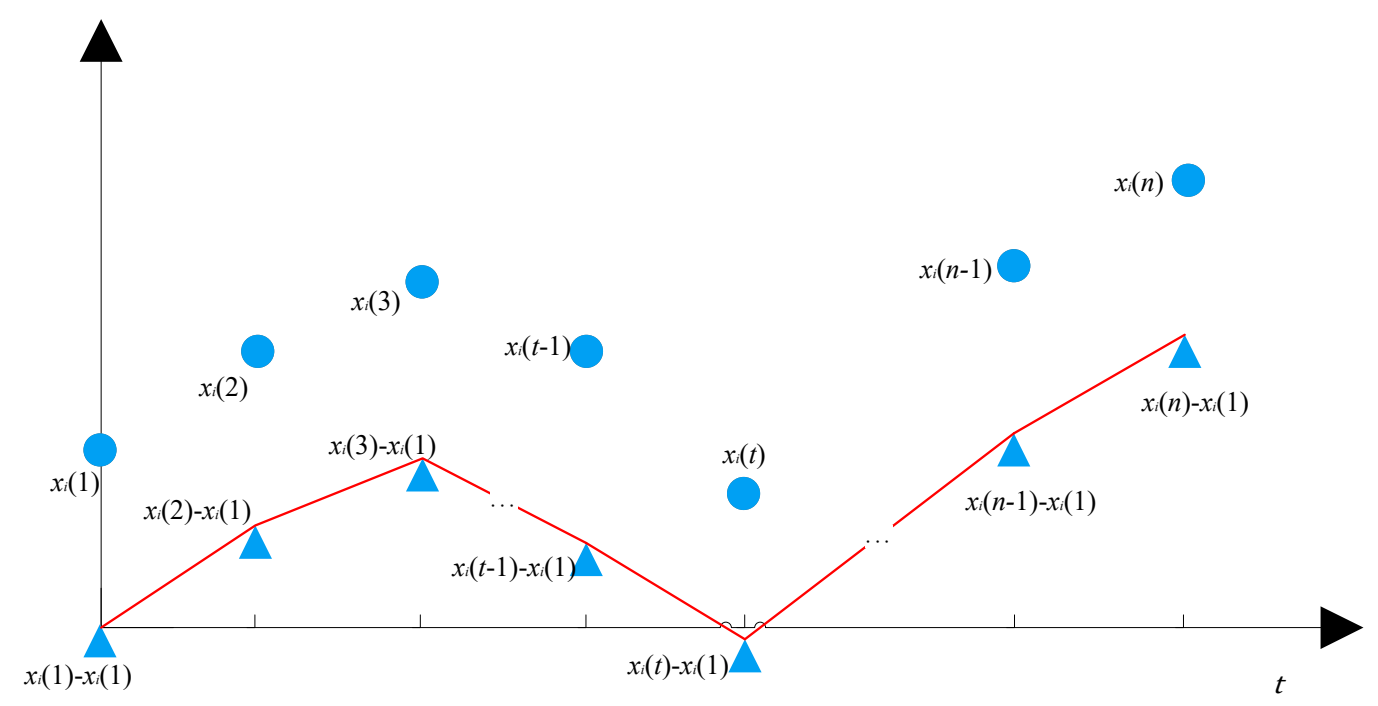

Figure 1. The broken line $X_{i}^{0}$.

Let

$$
\begin{gathered}
s_{i}=\int_{1}^{n}\left(X_{i}^{0}-X_{i}^{0}(1)\right) d t \\
s_{i}-s_{j}=\int_{1}^{n}\left(X_{i}^{0}-X_{j}^{0}\right) d t
\end{gathered}
$$


Hence, the absolute degree of grey incidence of $X_{i}$ and $X_{j}$ can be defined as

$$
\gamma_{i j}=\frac{1+\left|s_{i}\right|+\left|s_{j}\right|}{1+\left|s_{i}\right|+\left|s_{j}\right|+\left|s_{i}-s_{j}\right|}
$$

The upper triangular matrix calculated is as follows:

$$
\mathrm{A}=\left[\begin{array}{ccc}
\gamma_{11} & \cdots & \gamma_{1 m} \\
& \ddots & \vdots \\
& & \gamma_{m m}
\end{array}\right]
$$

where $\gamma_{i i}=1(i=1,2, \ldots, m)$.

Taking the threshold value $r \in[0,1], r>0.5$ is generally required; when $\gamma_{i j} \geq r(i \neq j), X_{i}$ and $X_{j}$ can be grouped into one class. The value of $r$ can be determined based on the specific situation and actual need, and an $\mathrm{r}$ closer to 1 indicates a narrower class and fewer materials in each class, accordingly. A smaller $\mathrm{r}$ indicates a broader class and, accordingly, in this case, more materials in each class.

\section{Case Study}

\subsection{Case Warehouse}

To emphasize the issues of the class-based model in Chinese flood control material reserve management, a case study was conducted.

The Jiangsu Provincial Hydraulic and Flood Control Material Reserve Center (HFCMRC) is a specialized establishment for flood control material reserves and their transportation in the Jiangsu Province, taking charge of reserving, management, allocation, and transportation of central and provincial flood-control material, and acting as a provincial flood control material reservation and management unit with the strongest emergency security capability in China, providing flood-fighting material support for flood control, disaster relief, and severe sudden disasters. HFCMRC has set up six provincial flood control material reserve warehouses including one central- and provincial-level flood-fighting warehouse in Zhenjiang. The Zhenjiang Warehouse, founded in the 1970s, is a the key warehouse in the Jiangsu province for flood-fighting material reserve, a central-level designated warehouse which is a flood control material reserve, a warehouse with the biggest scale and the most complete material varieties in Jiangsu Province, and the only central- and provincial-level flood-fighting material warehouse in Jiangsu Province. It is one of the most representative flood-fighting material reserve warehouses in China. For this reason, this study chose the HFCMRC Zhenjiang Warehouse as the case study example.

HFCMRC Zhenjiang Warehouse currently stores the following varieties of material: rubber dinghy, assault boat, life vest, outboard motor, woven bag, colour strip cloth, geotechnical cloth, square timber, lumps of wood, steel wire tuck net, tent, flood-control work light, generator unit, etc., fitted with mechanical equipment and auxiliary lighting facilities of all kinds. Zhenjiang Warehouse has completed tasks in flood control and emergency response in the Jiangsu Province in all the previous years and the allocation and transport of rescue supplies for the Wenchuan earthquake in 2008. It has been praised by State Flood Control and Drought Relief Headquarters and the Jiangsu Provincial Flood Control and Drought Relief Headquarters for its positive and significant contributions to the victories of flood control and emergency response.

Interviews, document analyses, and observations were conducted for the data collection of this case study. A series of face-to-face semi-structured interviews with managers and staff members from the flood control governments, food control materials governments, and food control materials enterprises were conducted. 


\subsection{Classification of Flood Control Materials}

The case warehouse currently has 14 types of provincial-level flood control materials in reserve, including block stones, metal wire nets, line throwing apparatuses, woven bags, tents (specially made for flood control), lighting vehicles, geotextiles, filter pads, life jackets, assault boats, dinghy, outboard motor, power generators, and wood. Among these items, the dinghy is made of rubber and must be kept at a constant temperature. Given this special requirement, the rubber dinghy is not considered in this paper because it is typically stored in a warehouse at a constant temperature. The outboard motor and rescue boats must be used as a package and, thus, are typically stored together. Considering the factors above, we selected 12 types of widely universal and highly practical materials to study in this paper. For this paper, we consider only the assault boat class, and the associated outboard motor class is adjacently stored. The selected key flood control materials are block stones $\left(\mathrm{X}_{1}\right)$, metal wire nets $\left(X_{2}\right)$, line throwing apparatuses $\left(X_{3}\right)$, woven bags $\left(X_{4}\right)$, tents (specially made for flood control $)\left(X_{5}\right)$, lighting vehicles $\left(X_{6}\right)$, geotextiles $\left(X_{7}\right)$, filter pads $\left(X_{8}\right)$, life jackets $\left(X_{9}\right)$, assault boats $\left(X_{10}\right)$, power generators $\left(X_{11}\right)$, and wood $\left(X_{12}\right)$. Statistics on the 12 classes of the Jiangsu provincial-level flood control materials are shown in Figure 2. The utilisation frequency is shown in Figure 3.

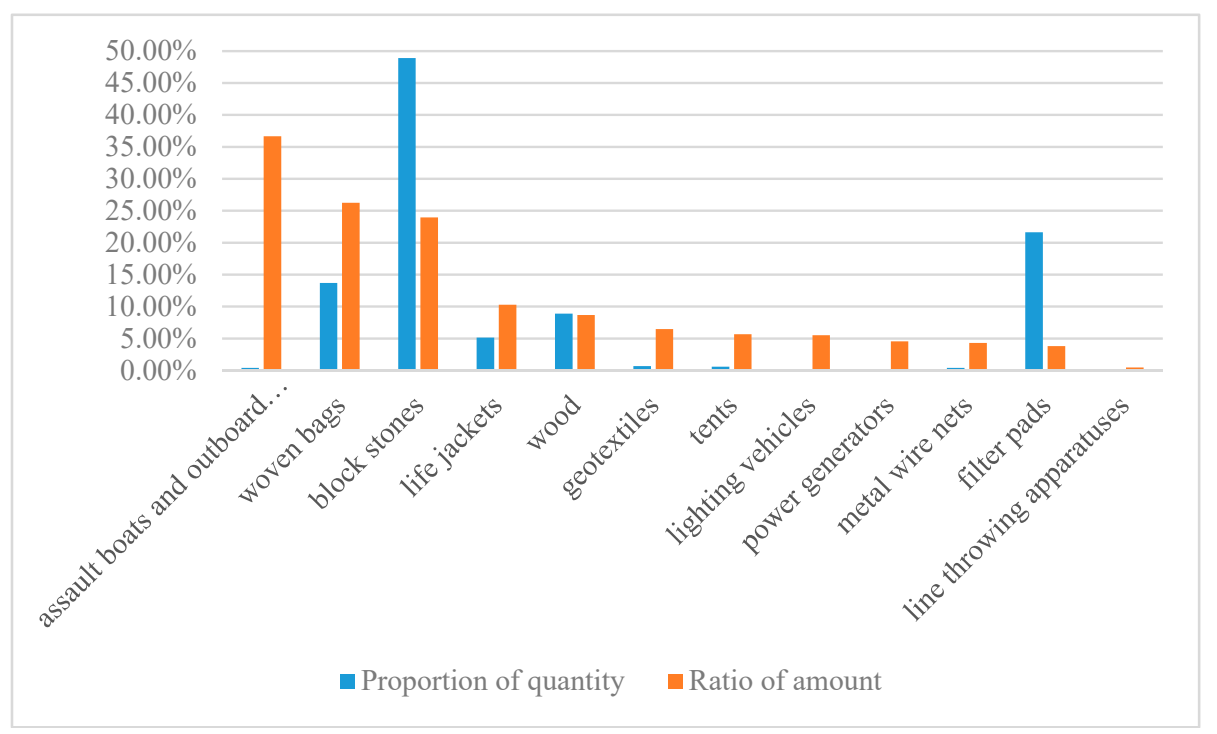

Figure 2. The statistics on the 12 classes of the Jiangsu provincial-level flood control materials. The proportion of quantity: the proportion of the amount of flood control materials in the total amount of provincial-level flood control materials in HFCMRC Zhenjiang Warehouse. The ratio of amount: the proportion of funds for flood control materials procurement in the total funds for provincial-level flood control materials procurement in the HFCMRC Zhenjiang Warehouse. 


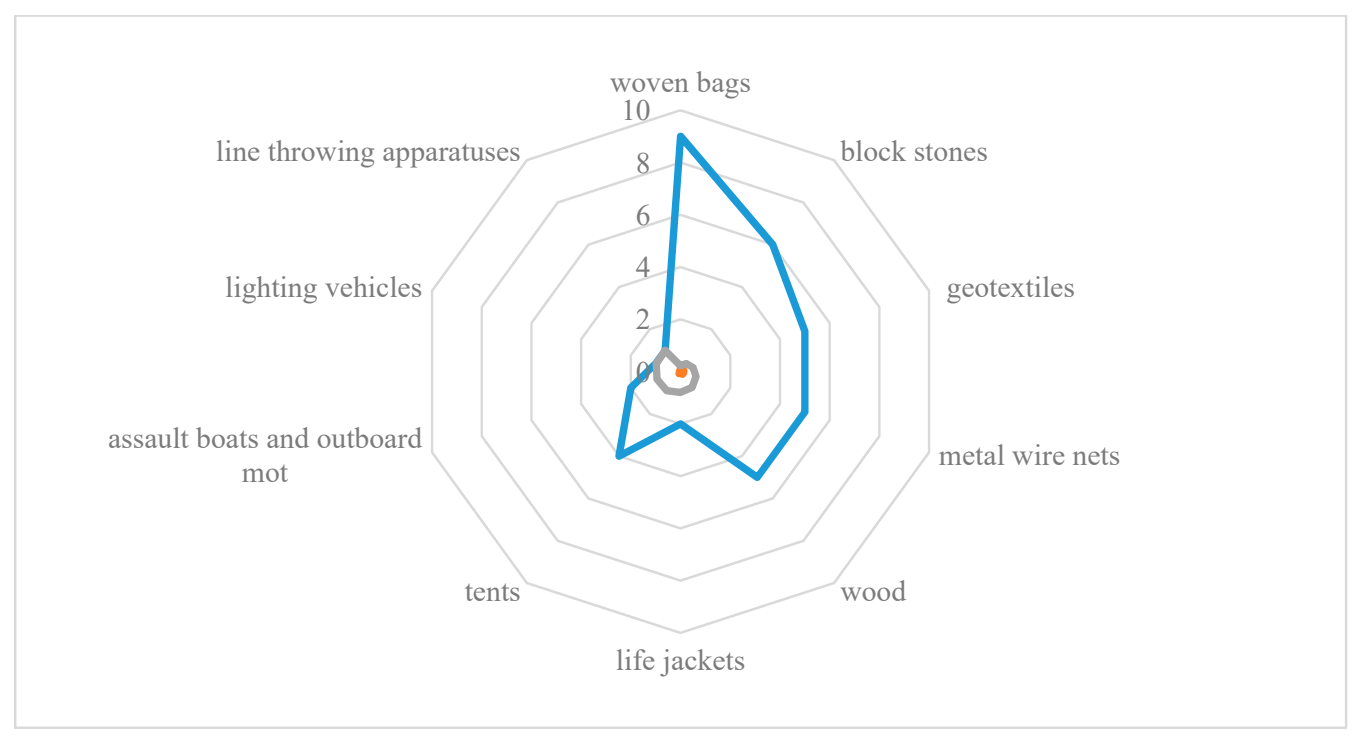

Figure 3. The utilisation frequency of the 12 classes of Jiangsu provincial-level flood control materials.

\subsection{Class-Based Evaluation Index System}

A three-tiered comprehensive class-based evaluation index system for flood control materials was constructed. Level 1 is the final target level, including three Level 2 indices. The Level 2 indices include the importance $\left(B_{1}\right)$, reserve $\left(B_{2}\right)$, and cost $\left(B_{3}\right)$ of the materials. Importance $\left(B_{1}\right)$ is the degree of importance of the flood control materials, reserve $\left(B_{2}\right)$ is the reserve attribute of the flood control materials, and cost $\left(\mathrm{B}_{3}\right)$ is the cost attribute of the flood control materials. Every Level 2 index can be further segregated into three levels of evaluation indices, including eight evaluation indices, such as urgency of demand $\left(C_{1}\right)$, shortage and loss $\left(C_{2}\right)$, utilisation frequency $\left(C_{3}\right)$, reserve life $\left(C_{4}\right)$, warehousing requirement $\left(C_{5}\right)$, purchasing costs $\left(C_{6}\right)$, transportation costs $\left(C_{7}\right)$, and storage costs $\left(C_{8}\right)$. See Figure 4 for details.

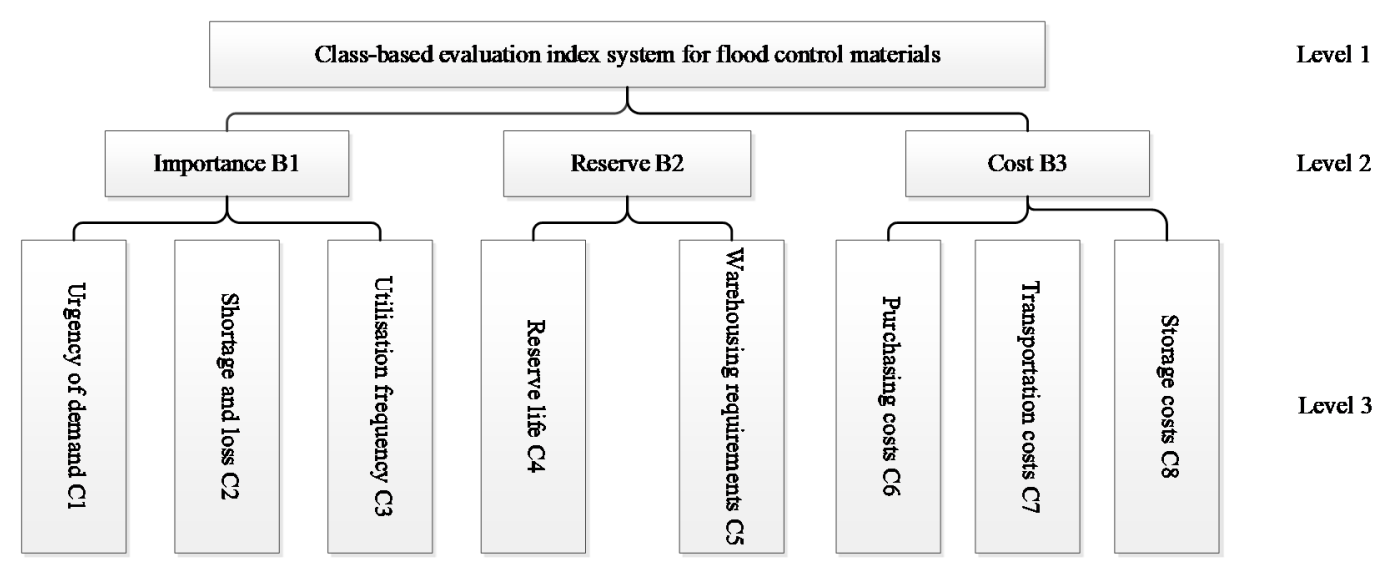

Figure 4. The evaluation index system and class-based model for flood control materials.

Experts for evaluating the weight and index mainly came from the relevant administrative departments related to flood control, as well as from rescue work, all-level units in reserving flood control materials, and research institutions. Weight and index evaluation are carried out by the Delphi expert method by 20 experts. Ultimately, three Level 2 weighted indices were derived: the weighted indices of importance $\mathrm{w}_{1}=0.5$, the weighted indices of reserve $\mathrm{w}_{2}=0.3$, the weighted indices of $\operatorname{cost} \mathrm{w}_{3}=0.2$. The scoring of the evaluation sets was obtained through consultation and face-to-face discussions with experts to give the experts a full understanding of the construction of the class-based index system for flood control reserve materials and its significance. 


\subsection{Grey Clustering Calculations}

Based on the class-based index system previously constructed, the Level 3 indices were quantified using the Delphi method, a 10-point expert scoring method: 10 points for very high, 8 points for high, 5 points for moderate, 2 points for low and 0 points for very low. The overall scores of the 8 Level 3 indices of the 12 classes of flood control materials are presented in Table 2.

Because the Level 3 evaluation index $C_{5}$ is a negative index relative to the Level 2 index, the reversion value $10-C_{5}$ is used when performing the conversion of the Level 3 evaluation index to the Level 2 index. Hence,

$$
\begin{aligned}
\mathrm{B}_{1} & =\frac{1}{3}\left(\mathrm{C}_{1}+\mathrm{C}_{2}+\mathrm{C}_{3}\right) \mathrm{w}_{1} \\
\mathrm{~B}_{2} & =\frac{1}{2}\left(\mathrm{C}_{4}+10-\mathrm{C}_{5}\right) \mathrm{w}_{2} \\
\mathrm{~B}_{3} & =\frac{1}{3}\left(\mathrm{C}_{6}+\mathrm{C}_{7}+\mathrm{C}_{3}\right) \mathrm{w}_{3}
\end{aligned}
$$

The weighted overall scores of the three Level 2 indices for the 12 classes of flood control materials obtained are presented in Table 3.

Table 2. The overall scores of the 8 Level 3 indices of the 12 classes of flood control materials.

\begin{tabular}{ccccccccc}
\hline Subitem & $\mathrm{C}_{1}$ & $\mathrm{C}_{2}$ & $\mathrm{C}_{3}$ & $\mathrm{C}_{4}$ & $\mathrm{C}_{5}$ & $\mathrm{C}_{6}$ & $\mathrm{C}_{7}$ & $\mathrm{C}_{8}$ \\
\hline $\mathrm{X}_{1}$ & 9.7 & 9.8 & 9.9 & 10 & 2.15 & 3.05 & 4.9 & 4.05 \\
$\mathrm{X}_{2}$ & 8.89 & 6.3 & 7.35 & 9.8 & 6.05 & 5.15 & 5.9 & 5.45 \\
$\mathrm{X}_{3}$ & 5.6 & 4.85 & 3.8 & 3.5 & 7.15 & 4.05 & 5.15 & 5.75 \\
$\mathrm{X}_{4}$ & 7.85 & 6.55 & 8.35 & 3.35 & 6.05 & 3.35 & 3.2 & 4.85 \\
$\mathrm{X}_{5}$ & 7.9 & 7.05 & 9.5 & 3.65 & 6.9 & 5.45 & 5 & 6.85 \\
$\mathrm{X}_{6}$ & 3.95 & 3.65 & 2.9 & 3.95 & 6.05 & 4.25 & 5.15 & 6.15 \\
$\mathrm{X}_{7}$ & 4.65 & 3.35 & 2.9 & 3.5 & 6.2 & 4.75 & 5.3 & 5.4 \\
$\mathrm{X}_{8}$ & 8.7 & 7.25 & 6.1 & 4.9 & 7.2 & 6.45 & 4.4 & 6.65 \\
$\mathrm{X}_{9}$ & 6.7 & 6.4 & 3.05 & 8.5 & 8.35 & 7.6 & 6.4 & 6.3 \\
$\mathrm{X}_{10}$ & 8.5 & 7.7 & 4.7 & 9.1 & 8.95 & 8.8 & 7 & 7.5 \\
$\mathrm{X}_{11}$ & 7.35 & 6.15 & 4.35 & 8.75 & 7.75 & 9.4 & 7.5 & 7.85 \\
$\mathrm{X}_{12}$ & 4.1 & 2.15 & 2.6 & 7.5 & 5.9 & 3.95 & 3.2 & 4.7 \\
\hline
\end{tabular}

Table 3. The weighted overall scores of the 3 Level 2 indices for 12 classes of flood control materials.

\begin{tabular}{cccc}
\hline Subitem & $\mathbf{B}_{1}$ & $\mathbf{B}_{2}$ & $\mathbf{B}_{3}$ \\
\hline $\mathrm{X}_{1}$ & 4.90 & 1.82 & 0.80 \\
$\mathrm{X}_{2}$ & 3.76 & 2.38 & 1.10 \\
$\mathrm{X}_{3}$ & 2.38 & 1.60 & 1.00 \\
$\mathrm{X}_{4}$ & 3.79 & 1.41 & 0.76 \\
$\mathrm{X}_{5}$ & 4.08 & 1.58 & 1.15 \\
$\mathrm{X}_{6}$ & 1.75 & 1.50 & 1.04 \\
$\mathrm{X}_{7}$ & 1.82 & 1.46 & 1.03 \\
$\mathrm{X}_{8}$ & 3.68 & 1.82 & 1.17 \\
$\mathrm{X}_{9}$ & 2.69 & 2.53 & 1.35 \\
$\mathrm{X}_{10}$ & 3.48 & 2.71 & 1.55 \\
$\mathrm{X}_{11}$ & 2.98 & 2.48 & 1.65 \\
$\mathrm{X}_{12}$ & 1.48 & 2.01 & 0.79 \\
\hline
\end{tabular}

The absolute degrees of grey incidence between $X_{i}$ and $X_{j}(\forall i \leq j(i, j=1,2, \ldots, 12))$ were calculated, and an upper triangular matrix for Level 2 indices is presented in Table 4. 
Table 4. The upper triangular matrix for the Level 2 indices.

\begin{tabular}{|c|c|c|c|c|c|c|c|c|c|c|c|c|}
\hline Subitem & $\mathbf{X}_{1}$ & $X_{2}$ & $x_{3}$ & $X_{4}$ & $\mathbf{X}_{5}$ & $x_{6}$ & $X_{7}$ & $\mathbf{X}_{8}$ & $X_{9}$ & $\mathbf{X}_{10}$ & $\mathbf{X}_{11}$ & $X_{12}$ \\
\hline$X_{1}$ & 1 & 0.86 & 0.74 & 0.64 & 0.89 & 0.75 & 0.64 & 0.64 & 0.82 & 0.75 & 0.63 & 0.90 \\
\hline$x_{2}$ & & 1 & 0.93 & 0.91 & 0.86 & 0.80 & 0.90 & 0.99 & 0.73 & 0.64 & 0.68 & 0.81 \\
\hline$x_{3}$ & & & 1 & 0.97 & 0.74 & 0.77 & 0.92 & 0.97 & 0.78 & 0.89 & 0.77 & 0.80 \\
\hline$X_{4}$ & & & & 1 & 0.84 & 0.79 & 0.96 & 0.92 & 0.88 & 0.72 & 0.65 & 0.84 \\
\hline$X_{5}$ & & & & & 1 & 0.75 & 0.64 & 0.64 & 0.92 & 0.75 & 0.63 & 0.80 \\
\hline$x_{6}$ & & & & & & 1 & 0.66 & 0.65 & 0.87 & 0.97 & 0.95 & 0.83 \\
\hline$X_{7}$ & & & & & & & 1 & 0.98 & 0.87 & 0.79 & 0.5 & 0.74 \\
\hline$x_{8}$ & & & & & & & & 1 & 0.66 & 0.78 & 0.87 & 0.73 \\
\hline$X_{9}$ & & & & & & & & & 1 & 0.79 & 0.65 & 0.85 \\
\hline$x_{10}$ & & & & & & & & & & 1 & 0.97 & 0.72 \\
\hline$X_{11}$ & & & & & & & & & & & 1 & 0.72 \\
\hline$X_{12}$ & & & & & & & & & & & & 1 \\
\hline
\end{tabular}

According to the incidence matrix, combined with the actual management of flood control materials, the threshold value $r=0.90$ is used. In the table, $r \geq 0.90$ indicates that there is a strong incidence between the two classes of flood control materials that can be grouped into one for partitioned storage management.

The clustering results based on Level 2 indices are as follows:

$$
\begin{gathered}
\mathrm{S}_{1}=\left\{\mathrm{X}_{1}, \mathrm{X}_{12}\right\} \\
\mathrm{S}_{2}=\left\{\mathrm{X}_{2}, \mathrm{X}_{3}, \mathrm{X}_{4}, \mathrm{X}_{7}, \mathrm{X}_{8}\right\} \\
\mathrm{S}_{3}=\left\{\mathrm{X}_{5}, \mathrm{X}_{9}\right\} \\
\mathrm{S}_{4}=\left\{\mathrm{X}_{6}, \mathrm{X}_{10}, \mathrm{X}_{11}\right\}
\end{gathered}
$$

To further highlight the attributes of all the classes of the flood control materials, they are further divided according to Level 3 evaluation indices. According to Table 2, the absolute degrees of the grey

\begin{tabular}{|c|c|c|c|c|c|c|c|c|c|c|c|c|}
\hline Subitem & $\mathbf{X}_{1}$ & $X_{2}$ & $x_{3}$ & $\mathbf{X}_{4}$ & $X_{5}$ & $x_{6}$ & $X_{7}$ & $X_{8}$ & $X_{9}$ & $\mathbf{X}_{10}$ & $\mathbf{X}_{11}$ & $X_{12}$ \\
\hline$x_{1}$ & 1 & 0.90 & 0.58 & 0.51 & 0.89 & 0.78 & 0.64 & 0.67 & 0.87 & 0.68 & 0.72 & 0.55 \\
\hline$x_{2}$ & & 1 & 0.90 & 0.99 & 0.79 & 0.86 & 0.68 & 0.71 & 0.77 & 0.81 & 0.78 & 0.56 \\
\hline$x_{3}$ & & & 1 & 0.92 & 0.60 & 0.64 & 0.77 & 0.73 & 0.60 & 0.58 & 0.67 & 0.80 \\
\hline$x_{4}$ & & & & 1 & 1 & 0.85 & 0.68 & 0.71 & 0.86 & 0.82 & 0.77 & 0.56 \\
\hline$X_{5}$ & & & & & 1 & 0.86 & 0.68 & 0.72 & 0.97 & 0.81 & 0.78 & 0.56 \\
\hline$x_{6}$ & & & & & & 1 & 0.75 & 0.80 & 0.88 & 0.90 & 0.95 & 0.58 \\
\hline$x_{7}$ & & & & & & & 1 & 0.93 & 0.69 & 0.65 & 0.83 & 0.66 \\
\hline$X_{8}$ & & & & & & & & 1 & 0.73 & 0.68 & 0.88 & 0.63 \\
\hline$X_{9}$ & & & & & & & & & 1 & 0.89 & 0.80 & 0.56 \\
\hline$x_{10}$ & & & & & & & & & & 1 & 0.93 & 0.55 \\
\hline$X_{11}$ & & & & & & & & & & & 1 & 0.60 \\
\hline$x_{12}$ & & & & & & & & & & & & 1 \\
\hline
\end{tabular}
incidence of $X_{i}$ and $X_{j}(\forall i \leq j(i, j=1,2, \ldots, 12))$ were calculated, and the upper triangular matrix for Level 3 evaluation indices was obtained, as presented in Table 5.

Table 5. The upper triangular matrix for the Level 3 evaluation indices.

Based on the calculations, the results of the final grey clustering analysis are as follows:

$$
\begin{gathered}
S_{1}=\left\{X_{1}\right\} \\
S_{2}=\left\{X_{2}, X_{3}, X_{4}\right\} \\
S_{3}=\left\{X_{7}, X_{8}\right\}
\end{gathered}
$$




$$
\begin{gathered}
\mathrm{S}_{4}=\left\{\mathrm{X}_{5}, \mathrm{X}_{9}\right\} \\
\mathrm{S}_{5}=\left\{\mathrm{X}_{6}, \mathrm{X}_{10}, \mathrm{X}_{11}\right\} \\
\mathrm{S}_{5}=\left\{\mathrm{X}_{12}\right\}
\end{gathered}
$$

\subsection{Results Analysis}

(1) The attributes of $X_{1}, X_{12}$ are prominent and are separated from the other classes. At the same time, according to the Level 2 indices, because $X_{1}$ and $X_{12}$ have a relatively high correlation (0.9), we may consider grouping these two types of materials, namely block stones and wood, into one class, placing them in the outfield and sheltering them from rain.

(2) $X_{2}, X_{3}, X_{4}, X_{7}, X_{8}$ can be grouped into one class. We can see from the results of classifying the Level 3 evaluation indices that the absolute degrees of incidence of $X_{2}$ and $X_{3}, X_{2}$ and $X_{4}$ are 0.90 and 0.99 , respectively, whereas the degree of incidence of $X_{7}$ and $X_{8}$ is 0.93 . However, the results of classifying Level 2 indices show that the absolute degrees of incidence of $X_{2}$ and $X_{3}, X_{4}, X_{7}, X_{8}$ are 0.93 , $0.91,0.90$, and 0.99 , respectively. After an overall consideration, we should group metal wire nets, line throwing apparatuses, woven bags, geotextiles, and filter pads into one class. Their common attributes are low costs, high utilisation frequency and low reserve requirements.

(3) The degrees of incidence of $X_{5}$ and $X_{9}$ in Level 2 indices and Level 3 evaluation indices are 0.92 and 0.97, respectively, allowing them to be grouped into one class. Tents and life jackets have the highest utilisation frequency, and their cost levels and reserve requirements are average. They rank relatively high in terms of importance.

(4) $\mathrm{X}_{6}, \mathrm{X}_{10}, \mathrm{X}_{11}$ can be grouped into one class. The degrees of incidence of their Level 2 indices are $0.97,0.95$, and 0.97 , and the degrees of incidence of their Level 3 evaluation indices are 0.90, 0.95, and 0.93 , so we can group lighting vehicles, assault boats and power generators into one class, They are characterised by a high importance and relatively high costs.

\subsection{Strategy Recommendation about Flood Control Materials Classified Storage}

In provincial flood control materials storage warehouses, the above materials are classified and stored according to factors such as importance, reserve, cost, and etc., such as putting metal wire nets, line throwing apparatuses, woven bags, geotextiles, and filter pads these similar materials together, storing tents, life jackets, and etc., in the same area, and placing lighting vehicles, power generators, and assault boats in the same area, etc. Then we locate the storage according to the size of the material. It is more appropriate to adopt a simple location storage strategy because flood control materials are generally relatively large and the frequency of storage is low.

\section{Conclusions}

By means of grey cluster analysis and evaluation, this paper comprehensively considers the three factors affecting the importance, cost, and reserve of flood control materials, and constructs a comprehensive evaluation index system of three levels of flood control materials based on the correlation between different types of materials. Taking the Zhenjiang Sub-center Storage of Flood Control Material Reserve Center of Jiangsu Province Water Resources for an example, we divide the flood control materials into four categories. By storing various types of materials in categories, it proposes classification storage strategies and classification management strategies to provide a scientific basis for flood control materials for the Jiangsu Province.

In the process of applying grey clustering analysis to the classified storage strategy of flood control materials, the following factors should be considered: (1) rationality of the index selection; (2) rationality of calibrating clustering weights and clustering coefficients; (3) the accuracy of model establishment, etc., to ensure the reliability and accuracy of the evaluation results. On the one hand, it is necessary to comprehensively and systematically understand the main factors affecting the classified storage strategy of flood control materials by investigating a large number of process examples, 
and making a scientific analysis and summary to form clustering indicators. On the other hand, it is necessary to learn from the experience of flood control materials storage, conduct a detailed investigation, analysis, and evaluation of existing experience strategies, and use mathematical tools to construct appropriate models to properly calibrate clustering weights and clustering coefficients so that the clustering calculation results are closer to the actual situation of flood control materials storage management. In this paper, only a few of the main factors are considered comprehensively. If the other factors can be considered more systematically, the applied method can give superior results to common sense, and the clustering results will be closer to the actual situation of flood control material reserve management.

Author Contributions: All authors contributed equally to this work. In particular, W.W. developed the original idea for the study and designed the methodology. L.H. revised the manuscript. W.L. drafted the manuscript. Y.Z. performed investigation and case study. P.J. performed data curation. D.P. helped develop the results analysis and further developed the review of the literature. All authors have read and approved the final manuscript.

Funding: This research was funded by the Humanities and Social Sciences of Ministry of Education Planning Fund (No. 18YJAZH092); Jiangsu Water Conservancy Science and Technology Project (No. 2017059 and No. 2018071); and the Fundamental Research Funds for the Central Universities (No. 2017B15614).

Acknowledgments: The authors would like to thank all the HFCMRC staff and especially Jianbin Wei, Yi Han and Jiang Liu for data collection.

Conflicts of Interest: The authors declare no conflict of interest.

\section{References}

1. Chang, M.S.; Tseng, Y.L.; Chen, J.W. A scenario planning approach for the flood emergency logistics preparation problem under uncertainty. Transp. Res. Part E 2007, 43, 737-754. [CrossRef]

2. Kates, R.W. Hazard and Choice Perception in Flood Plain Management; Department of Geo Research Paper no. 78; University of Chicago Press: Chicago, IL, USA, 1962.

3. Saddagh, M.H.; Abedini, M.J. Enhancing MIKE11 updating kernel and evaluation its performance using numerical experiments. J. Hydrol. Eng. 2012, 17, 252-261. [CrossRef]

4. Wang, W.; Huang, L.; Liang, X.D. On Simulation-based Reliability of Complex Emergency Logistics Network in Post-accident Rescue. Int. J. Environ. Res. Public Health 2018, 15, 79. [CrossRef] [PubMed]

5. Wang, W.; Huang, L.; Guo, Z.X. Optimization of Emergency Material Dispatch from Multiple Depot Locations to Multiple Disaster Sites. Sustainability 2017, 9, 1978. [CrossRef]

6. Garrido, R.A.; Lamas, P.; Pino, F.J. A stochastic programming approach for floods emergency logistics. Transp. Res. Part E Logist. Transp. Rev. 2015, 75, 18-31. [CrossRef]

7. Leeuw, S.; Vis, I.F.A.; Jonkman, S.N. Exploring logistics aspects of flood emergency measures. J. Conting. Crisis Manag. 2012, 20, 166-179. [CrossRef]

8. Alem, D.; Clark, A.; Moreno, A. Stochastic network models for logistics planning in disaster relief. Eur. J. Oper. Res. 2016, 255, 187-206. [CrossRef]

9. Hausman, W.H.; Schwarz, L.B.; Graves, S.C. Optimal Storage Assignment in Automatic Warehousing Systems. Manag. Sci. 1976, 22, 629-638. [CrossRef]

10. Larson, T.N.; March, H.; Kusiak, A. Heuristic approach to warehouse layout with class-bassed storage. IIE Trans. 1997, 29, 337-348. [CrossRef]

11. Thonemann, U.W.; Brandeau, M.L. Optimal storage assignment policies for automated storage and retrieval systems with stochastic demands. Manag. Sci. 1998, 44, 142-148. [CrossRef]

12. Park, B.C.; Foley, R.D.; Frazelle, E.H. Performance of miniload systems with two-class storage. Eur. J. Oper. Res. 2006, 170, 144-155. [CrossRef]

13. Ene, S.; Özurk, N. Storage location assignment and order picking optimization in the automotive industry. Int. J. Adv. Manuf. Technol. 2012, 60, 787-797. [CrossRef]

14. Brynzr, H.; Johansson, M.I. Storage location assignment: Using the product structure to reduce order picking times. Int. J. Prod. Econ. 1996, 46, 595-603. [CrossRef]

15. Mantel, R.J.; Schuur, P.C.; Heragu, S.S. Order oriented strategy for warehouse. Eur. J. Ind. Eng. 2007, 1, 301-316. [CrossRef] 
16. Li, M.L. Goods classification based on distribution center environmental factors. Int. J. Prod. Econ. 2009, 119, 240-246. [CrossRef]

17. Muralidharan, B.; Linn, R.; Pandit, R. Shuffling Heuristics for the Storage Location Assignment in an AS/RS. Int. J. Prod. Res. 2006, 33, 935-945. [CrossRef]

18. Arreola-Risa, A.; De Croix, G.A. Inventory management under random supply disruption and partial backorders. Int. J. Logist. 1998, 45, 687-703. [CrossRef]

19. Banomyong, R.; Sopadang, A. Using Monte Carlo simulation to refine emergency logistics response models: A case study. Int. J. Phys. Distrib. Logist. Manag. 2010, 40, 709-721. [CrossRef]

20. Gajpal, P.; Ganesh, L. Criticality analysis of spare using the analytic hierarchy process. Int. J. Prod. Econ. 1994, 35, 293-298. [CrossRef]

21. Axsater, S. A heuristic for triggering emergency orders in an inventory system. Eur. J. Oper. Res. 2007, 176, 880-891. [CrossRef]

22. Chang, S.H. Analysis of the Travel Distance and the Number of Storage Location for Storage Location Allocation Methods in a Warehouse System. J. Soc. Korea Ind. Syst. Eng. 2006, 29, 58-66.

23. Bai, X.Z.; Wang, Y.F.; Liu, H.N.; Guo, S. Symmetry Information Based Fuzzy Clustering for Infrared Pedestrian Segmentation. IEEE Trans. Fuzzy Syst. 2018, 26, 1946-1959. [CrossRef]

24. Son, L.H. DPFCM: A novel distributed picture fuzzy clustering method on picture fuzzy sets. Expert Syst. Appl. 2015, 42, 51-66. [CrossRef]

25. Guo, Z.X.; Zhang, Q. Application of fuzzy clustering analysis in classification of emergency materials. Comput. Eng. Appl. 2009, 45, 208-211.

26. Le-Duc, T.; De Koster, R. Travel distance estimation and storage zone optimization in a 2-block class-based storage strategy warehouse. Int. J. Prod. Res. 2005, 43, 3561-3581. [CrossRef]

27. Chen, H.; Xie, J.; Shen, Y.; Wang, N. Research on the Cooperative Inventory Models of Flood Prevention Materials. Syst. Eng.-Theory Pract. 2007, 27, 91-98.

28. Delgado, A.; Romero, I. Environmental conflict analysis using an integrated grey clustering and entropy-weight method. Environ. Model. Softw. 2016, 77, 108-121. [CrossRef]

(C) 2018 by the authors. Licensee MDPI, Basel, Switzerland. This article is an open access article distributed under the terms and conditions of the Creative Commons Attribution (CC BY) license (http://creativecommons.org/licenses/by/4.0/). 